\title{
LA INTELECCIÓN PRIMERA
}

THE FIRST INTELLECTION

\author{
Jacinto Choza ${ }^{1}$ \\ Universidad de Sevilla (España)
}

Recibido: $14-08-2014$

Aceptado: 10-09-2014

Resumen: Conocer es uno de los modos en que la vida se siente a sí misma. En el paleolítico los humanos expresan su saber de sí y del mundo mediante la actividad simbólica de los ritos. En el neolítico empiezan a expresar ese saber mediante signos, entonces es cuando se da la abstracción y la intelección. La poesía es el modo en que el signo puede referirse a la vida, expresarla y comprenderla.

Palabras-clave: intelección, luz, reflexión, símbolo, signo, poesía.

\begin{abstract}
Knowing is one of the ways in which life feels herself. In the Paleolithic humans express their knowledge of self and the world through the symbolic activity of the rites. In the Neolithic begin to express this knowledge through signs, that's when abstraction and insight is given. Poetry is how the sign can refer to life, express it and understand it.
\end{abstract}

Key-words: intellection, light, reflection, symbol, sign, poetry.

[1] (jchoza@us.es) Catedrático de Antropología Filosofía de la Universidad de Sevilla. Es miembro desde 1983 de "The New York Academy of Science", desde 1980 de la "American Anthropological Association", desde 1982 de la "Sociedad Andaluza de Filosofía" y desde 1994 de la "Sociedad Andaluza de Antropología”. Fundador y director desde1982 de Thémata. Revista de Filosofía de la Universidad de Sevilla; director del Departamento de Filosofía, Lógica y Filosofía de la Ciencia de la misma universidad (1995-1999); profesor Honorario de la Universidad de El Salvador (Buenos Aires, 1994) y de la Universidad del Norte (Asunción, Paraguay, 2011); fundador de la Sociedad Hispánica de Antropología Filosófica (SHAF) en 1996, y presidente en los bienios 1996-98, 19982000, 2000-2002 y 2002-2004; fundador y director del Seminario de las Tres Culturas de la Facultad de Filosofía de la Universidad de Sevilla desde 1999; fundador y director del Seminario sobre Identidad Cultural Latino Americana (SICLA), 2007. 


\section{El sentir primero}

Es imposible que la vida no se sienta a sí misma. Porque la vida es control de sí mismo por parte del viviente, acción que brota desde sí mismo y resultado de la acción que experimenta como redundancia en beneficio de sí mismo. Vida es inmanencia, in-manere, permanecer en sí mismo, y la inmanencia es vida.

Esta afirmación, que se ha repetido muchas veces y de diversas maneras desde Aristóteles y quizá desde antes, en el siglo XX ha sido expuesta y desarrollada en la cultura occidental por Michel $\mathrm{Henry}^{2}$, que añade a ella la tesis de que, para el viviente, para la vida, sentirse a sí misma es sentir su propio fundamento más allá del abismo, la tesis de que el sentirse a sí misma de la vida tiene una dimensión o un momento místico, de percepción de la divinidad o de contacto con ella.

Esta tesis, por otra parte, también ha sido desarrollada tanto filosófica como poéticamente en numerosas ocasiones. Filosóficamente tiene su desarrollo más conocido en el mundo académico occidental en la interpretación del Prólogo al Evangelio de San Juan que hiciera Fichte en el Tratado de la vida bienaventurada $a^{3}$, aunque Fichte no toma como punto de partida la experiencia del sentir o del sentir la vida sino la "experiencia" cartesiana contenida en la fórmula "pienso luego existo", o sea, una peculiar "experiencia de ser" o "experiencia del ser".

Poéticamente se encuentra en la tradición de la poesía y la mística sufí, en sus derivaciones hispánicas desde Teresa de Jesús a Juan Ramón Jiménez ${ }^{4}$, en el Haiku clásico japonés ${ }^{5}$ y otras tradiciones poéticas no occidentales, y especialmente en la poesía de Rilke.

"Sólo nosotros vemos muerte: El libre

Animal tiene tras de sí su muerte

Y ante sí a Dios, y cuando va, camina

por lo eterno lo mismo que las fuentes.

$$
\text { I.... I }
$$

¿Quién nos volvió del revés, para que siempre, por más que hagamos, tengamos el gesto del que se marcha?"6.

[2] Cfr. Michel Henry: Fenomenología de la vida, Madrid: Encuentro, 2013.

[3] Fichte: La exhortación a la vida bienaventurada o la Doctrina de la Religión. Estudio preliminar de A. Ciria; traducción de A. Ciria y D. Innnerarity. Madrid: Tecnos, 1995.

[4] Choza, J.: "La actitud religiosa de Juan Ramón Jiménez: Poesía y Revelación”, en Arrollo Arrayás, Luis M.: Juan Ramón Jiménez: Poesía y Pensamiento. Huelva: Servicio de Publicaciones de la Universidad de Huelva, 2008.

[5] Haya, Vicente: Haiku-dô: El haiku como camino espiritual. Barcelona: Kairós, 2007.

[6] Rilke, R.M.: Elegías de Duino. Elegía 8, inicio y final.

THÉMATA. Revista de Filosofía, $\mathrm{N}^{\circ} 50$ julio-diciembre (2014) pp.: 17-36 doi: 10.12795/themata.2014.i50.01 
Se trata ahora de hacer un examen filosófico, reflexivo, sobre este proceso también sumamente reflexivo de sentir la propia vida y su fundamento. Una dimensión, un momento o una fase de ese proceso es el conocimiento, el conocer. Vivir y sentir de algún modo que se vive pueden ser de suyo idénticos, pero también puede haber diferencia en esa identidad. El momento inicial, común y fundamentante de experimentar la propia vida es el sentir, el ser afectado. Aristóteles dice que el tacto es el fundamento de todos los sentidos y Heidegger que el comienzo de todo despliegue existencial es sentirse afectado, Befindlichkeit. A partir de ahí el vivir, y el conocer, se refractan en múltiple direcciones.

El vivir y el conocer se despliegan en múltiples vivientes y formas de vida, en todas las cuales se da la reflexión en un grado u otro, quizá también en el sentido de que en todas las formas de vida se da la reflexión que alcanza el fundamento del propio vivir. No hay muchos estudios filosóficos sobre este último punto, aunque es muy relevante la concepción pampsiquista de Leibniz, pero sí bastantes escritos poéticos y religiosos, de entre los cuales son bien conocidos en occidente el Cántico de las criaturas de Francisco de Asís ${ }^{7}$, y también algunos poemas de Juan Ramón Jiménez o de Rilke, que experimenta y vive "las fatigas de un escarabajo" y "el canto de las piedras".

Las diferentes formas de conocimiento, especialmente el pensamiento representativo, que es el desarrollado más profusamente en la cultura occidental, es una modalidad de la reflexión, del tacto.

El tacto es una reflexión porque es el modo en que un viviente siente que pesa o que flota, siente frío o calor, siente dolor y placer. Es el modo en que una materia animada se experimenta a sí misma en un determinado tipo de congruencia o incongruencia con la materia no animada, y desde luego también con otros organismos animados. Quizá los vegetales tengan una percepción de ese tipo de la luz y la oscuridad, y los microorganismos también.

El olfato y el gusto también se activan por contacto y penetración de unos corpúsculos ajenos en otros integrados en el cuerpo animado. Y el oído y la vista igualmente se activan por contacto de determinadas ondas sobre membranas receptoras del organismo viviente.

Conocer, percibir o sentir es siempre y en primer lugar reflexión sobre lo que le pasa al organismo, le afecta o le toca, y por eso no hay conocimiento que no sea tacto, contacto. Lo que puede ocurrir es que el conocimiento se despliegue en simultaneidad con un contacto ininterrumpido, o bien como elaboración de contactos interrumpidos que dejan una huella, una información, que se divide y compone con otras informaciones a nivel imaginativo o a nivel intelectivo.

[7] Francisco de Asís: Cántico de las criaturas, en Lírica románica medieval - Volumen1 - Murcia, Publicaciones Universidad de Murcia, 1986.

THÉMATA. Revista de Filosofía, №50 julio-diciembre (2014) pp.: 17-36

doi: 10.12795/themata.2014.i50.01 
En el nivel fundamental del tacto lo que se siente, se valora, orienta y guía el conocimiento es el bien. Se denomina bien a lo primero que se conoce y que abre la vida a ulteriores conocimientos y goces, y mal a lo que la cierra. Lo que emite algún tipo de señales y le hace a la vida experimentarse a sí misma como anhelo de más es el bien: anhelo de calor, de luz, de agua o de aire. El bien es experimentarse a sí misma como puro anhelo de algo otro que la salve de apagarse, extinguirse, dejar de sentirse y dejar de vivir.

Este tipo de vivencia es propia de todos los vivientes, desde el paramecio hasta el homo erectus y las diversas especies del homo sapiens.

A medida que los organismos vivientes son más complejos y tienen una mayor dotación de funciones cognoscitivas, el modo en que la vida se experimenta a sí misma y el modo en que se produce la reflexión cognoscitiva sobre lo que le afecta y le toca es diferente.

En el caso del homo sapiens el sentir se amplía al ser acogido en sucesivos ámbitos o formas de conciencia, y también, correlativamente, el vivir en tanto que saber de sí se va ampliando de manera que puede llegar a entrar en contacto con todo y a experimentarlo y conocerlo todo reflexivamente.

La cantidad y variedad de los elementos del universo parece que pueden ser vividos, sentidos y experimentados si entran en contacto con un tipo de materia animada dotada con receptores muy diversificados, a saber, los organismos de los mamíferos superiores. Y al parecer, la conciencia de todos esos contactos, cada uno de los cuales es conciencia de diversas formas de vida y tal vez del fundamento de todas esas formas desde la particularidad de cada una, es una y unifica o puede unificar las experiencias de todas esas formas de vida $\mathrm{y}$ sus fundamentos en una experiencia.

Dicho de otro modo, el intelecto, al parecer, es conciencia de sí como conciencia del ser-vivir del viviente, de las formas de vida, y como conciencia del fundamento de esas formas más allá del abismo. A la vez, es conciencia del ser, aunque hay experiencia de la diferencia entre el ser y la vida, y experiencia táctil, reflexiva táctil de esa diferencia, y seguramente también hay experiencia táctil de la indiscernibilidad del ser y de la vida.

La experiencia de la diferencia entre el ser y la vida es la bifurcación de la experiencia estética o táctil originaria, en experiencia filosófica y experiencia religiosa, y la experiencia de la indiferencia entre la vivencia del ser y la vivencia de la vida es la experiencia de la no bifurcación de la experiencia estética, sino de la unidad de ella con la filosófica y la religiosa, que es la experiencia mística. La experiencia mística en general, y los diferentes tipos de experiencia mística. 


\section{Oscuridad y silencio. El Phanum y el Mysterium}

La amplitud y profundidad de una capacidad cognoscitiva a nivel sensorial comparece cuando se produce una deprivación de objeto sensible. Si se trata de una deprivación de objeto visible y objeto audible, esa capacidad aparece como atención de la vista y del oído ante la oscuridad y ante el silencio, que distinguimos bien de la ceguera y de la sordera porque en éstas no se da actualidad de capacidades sensibles, sino sencillamente incapacidad.

La oscuridad y el silencio actualizan y muestran la capacidad de atención táctil, visual y auditiva, del viviente, y apuntan al correlato tangible, cognoscible-valorable de lo visible y audible. A su vez, la interrogación y admiración intelectivas actualizan y muestran la capacidad no táctil, intelectiva y comunicativa del intelecto, que opera componiendo huellas de lo tocado, o sea desplegando lo que se llama "logos" humano, y apuntan a su correlato tangible, o sea, inteligible-valorable y gozable-expresable. La profundidad del preguntar, del temor reverencial y de la admiración humana son insondables, no tienen fondo, son infinitos, porque son la reacción del espíritu ante lo ignoto y misterioso de sí mismo, de su ser-vivir, que se supone correlativa del ser en general. Por eso las respuestas que se dan a sus preguntas, los motivos que atribuyen a sus grandes temores, la dignidad con la que revisten a los valores venerados y el alcance y metas que confieren a su deseo de saber, también son infinitos, tienen la amplitud del vivir, del intelecto y del logos. Sus preguntas, respuestas y valoraciones se expresan en ritos, en unos ritos tan variados, de tanto alcance simbólico y de tanto valor artístico.

Los primeros sapiens despliegan su vivir, su intelecto y su logos, en esa lucha por la supervivencia. Cada éxito en el intento les abre el camino de lo que tiene sentido para ellos, de lo que genera vida y la preserva. El conjunto de la acción realizada y el objetivo alcanzado iluminan su ser-vida, su existencia, y la salvan. En otro caso el resultado es la muerte. Se repite lo que ha dado buen resultado, una y otra vez, y así se generan ritos, pautas de comportamiento, y se rotura el mundo. El universo queda colonizado porque queda iluminado, queda descubierto el sentido de algunos eventos y de las realidades relacionadas con ellos ${ }^{8}$. "Sentido" quiere decir utilidad, inteligibilidad, gozabilidad de lo vivido, de lo sentido-tocado. "Sentido" quiere decir "bien".

Fuera de ese foco de luz, de ese foco de los eventos con sentido, todo es caos, peligro y mal, o sea, oscuridad y silencio para un intelecto que escudriña el horizonte, que interroga y se admira ante la nada y la luz. El foco de luz es también misterio, enigma y pro-vocación de la interrogación sobre lo insondable. Permite comprender el peligro y la salvación. La oscuridad y

[8] Knight, Cris; Studdert-Kennedy, Michael and Hurford, James: The Evolutionary Emergence of Language Social Function and the Origins of Linguistic Form. Cambridge, UK: Cambridge University Press, 2000.

THÉMATA. Revista de Filosofía, $\mathrm{N}^{\circ} 50$ julio-diciembre (2014) pp.: 17-36

doi: 10.12795/themata.2014.i50.01 
el silencio por una parte, y el caos por otra, ponen de manifiesto que la vida queda entregada o confiada al protagonismo del conocimiento, del intelecto, o sea, queda confiada al protagonismo de la libertad, que aparece a su vez como diferencia entre vivir-ser y conocer-actuar en primer lugar, y como diferencia entre conocer-actuar y pausa en el conocer, como diferencia entre contacto y no-contacto con realidades ajenas al organismo, como diferencia entre entrega al contacto con lo otro y pausa y ensimismamiento.

El contacto con la información, con lo iluminado y sonoro, y la experiencia de la oscuridad y el silencio, proporcionan la experiencia del espacio y del tiempo, o de la amplitud infinita de lo inorgánico de lo cual se compone lo orgánico, lo vivo.

La luz, la comprensión, ilumina muchas realidades y permite captar el sentido de muchas realidades. El sentido es afirmación de la vida, es sobrevivir, es más vida y es salvación. La experiencia del vivir y sobrevivir mediante la caza y mediante la comida, mediante el sol que alumbra el campo de caza, mediante el fuego que alumbra el interior de la cueva en que se caza, se cocina y se come, y mediante la sangre que anima a los vivientes y se derrama en la caza y en la comida, es la experiencia de lo tangible y lo tocado actualmente y la experiencia de lo tangible pero no tocado actualmente sino representado, la experiencia de lo real, y también de la salvación, del milagro, de lo sagrado.

Se pueden describir los orígenes del vivir y el conocer humanos como una experiencia maravillosa, peligrosa, fascinante y sobrecogedora, como descubrimiento de "la realidad", como primera experiencia del "comprender", como un deslumbramiento ante la vida y el ser. ¿Y cómo no venerar a eso que da luz, que salva del caos, de la muerte, de la nada? .

La magnitud de lo que en esas experiencias de lo real y de lo sagrado vive el sapiens en la caza, en la lluvia, en el parto, en contraste con lo que experimentan otros vivientes, es la magnitud de la diferencia entre un viviente orgánico dotado de intelecto, de conciencia intelectual, y un viviente orgánico que no tiene esa dotación.

Esa experiencia perceptiva, estética, tiene como se ha dicho dos dimensiones y se bifurca en dos direcciones, una "puramente" o "meramente" cognoscitiva, que también se puede llamar experiencia "ordinaria", de lo cotidiano, de lo profano, experiencia de lo no tocado actualmente y "experiencia filosófica", y otra valorativa volitiva, que también se puede llamar experiencia de contacto con lo vivo, con la vida, con lo que fundamenta la vida más allá del abismo, o experiencia de lo sagrado y experiencia religiosa.

El origen y desarrollo de la experiencia y la actividad cognoscitiva es un acontecimiento que tiene siempre y en todo caso un carácter ordinario, pero a la vez y en continuidad con ello, un carácter extraordinario, deslumbrante, revelador, misterioso más que comprensible, y en último término, sagrado, religioso.

[9] Eliade, M.: “Experiencias de la luz mística”, en Mefistófeles y el andrógino, Barcelona: Labor, 1984.

THÉMATA. Revista de Filosofía, Nº50 julio-diciembre (2014) pp.: 17-36 doi: 10.12795/themata.2014.i50.01 
Una de las raíces de los vocablos que designan lo sagrado en las lenguas europeas, es la del término griego Phanaios, lo que ilumina, trae a la luz, da luz, del verbo Phaino, hacer aparecer, revelar, descubrir, brillar ${ }^{10}$, y del sustantivo phanós, antorcha, linterna, lámpara. A estos significados se suman los derivados del latín, fanum, templo, y pro-fanus, lo que está antes y fuera del templo y el término de las lenguas vernáculas fanatismo ${ }^{11}$. Este término, y las realidades designadas con él, son los signos en que se condensa, en algunas culturas de occidente, la representación del "sentido", del valor positivo, del bien de una serie de realidades y de actividades en las que sus creadores han experimentado el fundamento de la vida.

El Phanum, la luz, lo sagrado, lo que impone temor reverencial y atrae seduciendo, lo que se venera, aquello a lo que el hombre se entrega porque es lo que máximamente adora, ama e idolatra, en el sentido propio del término, es el fundamento de la vida más allá del abismo, que se llama "misterio" para significar que está más allá de la comprensión que el hombre puede alcanzar, por mucha experiencia táctil que tenga de ello.

En relación con el vocablo fanatismo, el termino idolatría proviene de los vocablos griegos eidos, idea, imagen, y latreia, adoración, culto ${ }^{12}$. El término eidos da lugar a 'idea' que en las lenguas europeas significa representación conceptual o imaginativa (más bien verdadera) y a 'ídolo', que en esas lenguas significa representación conceptual o imaginativa más bien falsa. "Verdadero" quiere decir que pone en contacto con lo vivo o con su fundamento, y "falso", que no pone en contacto.

Una cierta diferencia entre el Phanum, la luz, y el Eidos, la figura, la idea, lo iluminado, es que la luz ilumina sin tener forma mientras que la figura o la idea tiene forma y cuando ilumina lo hace de otro modo. Esto significa que desde cierto punto de vista no cabe una representación verdadera del Phanum, del ser, del bien, de la belleza o de la comunicación, no cabe una representación de lo que alumbra mediante un elemento opaco que pretendiera hacer de significante. Es decir, no cabe una representación 'objetiva' del Phanun, y a su vez, como contrapartida, lo representado o lo visto es representable y visible porque no es luz. La experiencia de la luz, del "sentido", siempre es táctil, y la "idea" o la "forma" siempre es opaca, y siempre es construida o replicada cognoscitivamente. La "experiencia filosófica" es, por una parte, experiencia táctil de la vida, de la luz, del sentido, del Phanum, y por otra parte, experiencia cognoscitiva, no táctil, de la idea, de la forma, de la cosa real o del acontecimiento conocido.

Platón suele describir el conocer como acontecimiento en el que el anhelo vital del hombre toca y ve el sentido o el bien de las realidades gracias al

[10] Liddell \& Scott's, Greek - English Lexicon, Oxford, clarendon, 1991, p. 854.

[11] Corominas J.: Breve diccionario etimológico de la lengua castellana. Madrid: Gredos, 1987, p 266. Con este sentido emplea Heidegger el sustantivo alemán Lichtung para significar claro del bosque y también conciencia, ámbito de la conciencia. Cfr., Carta sobre el humanismo.

[12] Lydell and Scott, Greek - English Lexicon, Oxford, 1991.

THÉMATA. Revista de Filosofía, N50 julio-diciembre (2014) pp.: 17-36

doi: 10.12795/themata.2014.i50.01 
bien o a la "luz" que emana del "eidos" y que "ilumina" la realidad que resulta conocida, pero en la tradición occidental los términos "idea" y "forma" designan generalmente lo opaco (aunque tenga una cierta luz propia), la parte pasiva, la parte conocida del fenómeno del conocimiento. Aristóteles suele describir el conocer como el acontecimiento en el que el anhelo vital humano toca y ve el "significado" la "forma" o el "eidos" de las realidades, gracias a la luz que emana del intelecto, y en la tradición occidental el intelecto y la luz designan la parte activa del conocimiento, que es incognoscible .

$\mathrm{Ni}$ el "eidos" de Platón ni el intelecto de Aristóteles, en la medida en que son Phanum, luz, tienen forma, y en la medida en que carecen de forma son incognoscibles en sí mismos y se relacionan con lo sagrado, con el misterio. Sus comentaristas posteriores han interpretado esa relación de diversas maneras, como semejanza, como identidad, como participación de lo divino en el hombre, como inhabitación directamente de lo divino en el alma humana o como inhabitación de toda alma humana en la luz del ser divino o en la luz del ser en tanto que creado. Entre los seguidores de Platón y en el seno del platonismo se han desarrollado doctrinas religiosas, pero no en el aristotelismo, y eso a pesar de que el dios de Aristóteles es subjetividad de un modo mucho más neto y claro que el de Platón.

Todas esas interpretaciones son maneras de responder a la pregunta sobre qué es lo que siente la vida cuando se siente a sí misma y a su fundamento, en el caso de un ser con una dotación cognoscitiva tal que su conciencia de sí es un intelecto de un alcance infinito.

Ahora hay que ver más detenidamente el tránsito y el desarrollo desde esa experiencia estética de la vida, que es propia de los humanos en los primeros milenios de su existencia, en los primero 130 o 140 milenios quizá, hasta el desarrollo de la experiencia cognoscitiva de la vida y de la realidad, que es donde se produce lo que actualmente se entiende por intelección, y que pertenece a esa fase de la historia de la especie humana denominada neolítico iniciada hacia el milenio 15 a. C. Hay que examinar la relación entre la experiencia táctil de la vida y de su fundamento, y la experiencia cognoscitiva de la vida, la experiencia no táctil y no tangible de lo real, la experiencia de lo representado.

\section{Pensamiento simbólico y pensamiento representativo de signos}

La conciencia intelectual humana no tiene una dotación cognoscitiva estable y constante, sino que, al igual que los vivientes orgánicos, crece, se desarrolla, y adopta configuraciones cuyas fases y formas no es posible precisar todavía en los 150.000 años de existencia que al parecer, tiene la especie.

Lo que resulta posible decir ahora es que desde el paleolítico al neolítico el intelecto humano ha desplegado unas modalidades de vida y de conocimiento 
muy variadas basadas en lenguajes performativos simbólicos, y que desde comienzos del neolítico hasta comienzos del milenio $3 \mathrm{~d}$. C. ha desplegado unas modalidades de vida y de conocimiento más homogéneas y con más comunicación entre sí, basadas en lenguajes predicativos de signos.

Estos tipos de lenguaje son correlativos de dos grandes tipos de pensamiento, para los cuales la vida y el fundamento de la vida se dan de modos diferentes, y el contacto con ellos, también. En concreto en el pensamiento lingüístico significativo no hay contacto inmediato con la vida, y se da una soberanía de la libertad y la reflexión intelectiva sobre la vida y la naturaleza que no se da en el pensamiento simbólico.

Para percibir esta diferencia hay que examinar comparativamente la estructura significativa de los símbolos y de los signos ${ }^{13}$.

El símbolo tiene carácter natural, es un elemento de la naturaleza y tienen un uso análogo en las distintas culturas paleolíticas. Los símbolos utilizados en el arte parietal y el arte mueble, tienen como significantes realidades naturales, y tienen como significados también realidades naturales ${ }^{14}$.

Estas características de los significantes y los significados de los símbolos paleolíticos pueden percibirse con claridad en el siguiente cuadro.

\begin{tabular}{|l|l|l|l|}
\hline Símbolo significante & Significado & Símbolo significante & Significado \\
\hline Tierra & Refugio/ infierno & Toro & Fuerza \\
\hline Aire & Alma / vida & Caballo & Hembra \\
\hline Agua & Vida/ fecundidad & Pájaro & Alma del difunto \\
\hline Fuego & Poder / divinidad & Vulva & Hogar / vida \\
\hline Luna & Menstruación & Pechos (pezones) & Hogar/ alimento \\
\hline Leche & Madre & Semen & Primavera \\
\hline Sangre & Vida & Falo & Poder / Padre \\
\hline
\end{tabular}

Cuando se trata de signos, que son grafismos convencionales, y no de símbolos, que son realidades naturales, el tipo de referente o de significado al que el significante remite, no pertenece al orden real, sino a un orden nuevo que es precisamente el orden intencional, abstracto o ideal. El conocimiento y la vida empiezan a referirse también a ese nuevo orden. Durante algunos milenios se refieren indistintamente a los dos órdenes, pero poco a poco se van refiriendo cada vez más al orden intencional de los signos y cada vez menos al orden real de los símbolos, y los significados a los que se refieren la vida y el co-

[13] Se reproduce aquí el parágrafo 39 a de J. Choza: Filosofía de la cultura, Sevilla, $2^{\mathrm{a}}$ ed. 2014. [14] Ries, Julien, Le symbolisme dans le culte des grandes religions : actes du Colloque de Louvain-La-Neuve: 4-5 octobre 1983, Louvain-la-Neuve : Centre d'Histoire des Religious, 1985; cfr. Lo sagrado en la historia de la humanidad, Madrid, Encuentro, 1989.

THÉMATA. Revista de Filosofía, $\mathrm{N}^{\circ} 50$ julio-diciembre (2014) pp.: 17-36 doi: 10.12795/themata.2014.i50.01 
nocimiento van dejando de tener un carácter real y natural para pasar a tener un carácter más bien ideal y objetivo. El contraste entre los significados de los símbolos y los de los signos puede exponerse en el siguiente cuadro.

\section{Símbolo}

\section{Signo}

\begin{tabular}{|l|l|l|l|l|}
\hline & $\begin{array}{l}\text { Características del } \\
\text { Significante } \\
\text { (Natural) }\end{array}$ & $\begin{array}{l}\text { Características del } \\
\text { Significado } \\
\text { (Real) }\end{array}$ & $\begin{array}{l}\text { Características } \\
\text { del Significante } \\
\text { (Artificial) }\end{array}$ & $\begin{array}{l}\text { Características } \\
\text { del Significado } \\
\text { (Ideal) }\end{array}$ \\
\hline 1 & Presente & Futuro/ más allá & Presente & Atemporal \\
\hline 2 & Singular & Universal concreto & Singular & Universal \\
\hline 3 & Empírico & Transcendente & Empírico & Objetivo \\
\hline 4 & Contingente & Necesario & Contingente & Necesario \\
\hline 5 & Elegido/espontaneo & Ser real & Elegido/arbitrario & Esencia inteligible \\
\hline 6 & Operante & Activo & Inoperante & Inactivo \\
\hline 7 & Eficaz & Eficaz & Ineficaz & Ineficaz \\
\hline 8 & Polisémico & Eficacia plural & Unívoco & Unívoco \\
\hline
\end{tabular}

Con estas características, el símbolo tiene valor de revelación, por una parte, y de adivinación, por otra. De revelación, porque hace manifiesta en el significante una realidad oculta, que es la del significado. De adivinación, porque hace presente en el significante algo que pertenece al futuro o al más allá, que es el orden del significado. El símbolo dice lo que las cosas han sido, son y serán ${ }^{15}$.

Conforme se avanza en el neolítico los símbolos van convirtiéndose en pictogramas primero y en signos abstractos y convencionales después. Durante varios milenios mantienen a la vez las características de símbolos y de signos, hasta que finalmente pierden las de los símbolos.

Cuando los símbolos se convierten en signos, entonces los iconos, los gestos y los gritos de los rituales pasan a ser proposiciones y se inicia el uso generalizado del lenguaje predicativo.

El conocimiento humano se construye y se despliega al menos en dos niveles, el del orden trascendental y el del orden predicamental. El conocimiento que opera en el orden trascendental rige para todos los hombre de todos los tiempos y se basa en los primeros principios y en las formas de oposición entre los cuatro grandes tipos de significaciones (proposiciones) que Aristóteles sistematiza en el Peri hermeneias y donde taza el cuadrado lógico. Estos

[15] Ries, op. cit.

THÉMATA. Revista de Filosofía, Nº50 julio-diciembre (2014) pp.: 17-36 doi: 10.12795/themata.2014.i50.01 
principios lógicos rigen todas las formas de conocimiento, de comprensión y de comunicación del vivir humano en todos los tiempos, desde la aparición de la especie en el milenio 150 a. C. en África.

El conocimiento que opera en el orden predicamental rige para la cultura que ha generado el sistema categorial que le es propio. En el paleolítico los sistemas categoriales usados por las diferentes tribus de cazadores recolectores son muchos. Cuando las diferentes culturas se inician en las formas de vida neolíticas se inicia un nuevo tipo de conocimiento, basado en los mismos principios del orden trascendental vigente antes y siempre, pero con novedades muy notables.

El orden del conocimiento representativo de la realidad, que es el orden intencional o el orden objetivo, es inaugurado en el neolítico y se consolida a lo largo del neolítico y calcolítico, (entre el milenio 12 y el 1 a. C.) que es cuando se consolida la vida urbana, el lenguaje predicativo y la escritura. Lo que los filósofos occidentales del siglo XX llaman el mundo intencional, el mundo eidético, la objetualidad, el origen de la geometría, de la filosofía y de las ciencias en general, aparece al final del proceso de formación del sistema categorial de las culturas neolíticas, que es el que describe Aristóteles en Categorías $^{16}$. Ese proceso es perceptible en el examen de las diversas especies de la categoría de "cantidad"17.

La consolidación del plano de representación abstracta en el que se generan y articulan las herramientas y artefactos técnicos como los templos, los navíos, los canales y los puertos, los sistemas de contabilidad de producción y almacenamiento de grano, los títulos de propiedad, la escritura y el lenguaje predicativo lleva consigo que el hombre neolítico, al contrario del hombre paleolítico, viva más en relación con el mundo eidético que con el mundo natural.

Por eso tiene cada vez menos experiencia estética, táctil, de la vida y del fundamento de la vida, y más experiencia cognoscitiva de las representaciones del mundo eidético. En esa situación es cuando nace la filosofía y nacen las ciencias. Surgen a partir de experiencias y vivencias estéticas, de la luz y del bien, de la vida y de sus representaciones en la belleza de los números y en la belleza y profundidad de las expresiones verbales, poéticas y filosóficas, y se desarrollan como construcciones cognoscitivas. Esas experiencias estéticas-cognoscitivas tienen, como se ha dicho, un momento de experiencia del fundamento de la vida, de experiencia religiosa. Por eso se señala ese fundamento, y la "experiencia" de ese fundamento, en los diferentes momentos en que la filosofía ha vuelto a empezar por su principio y por su fundamento, aunque con el enfoque peculiar propio del momento histórico en que se produce.

[16] Estas tesis están desarrolladas en Choza, J.: Filosofia de la Cultura, Sevilla, Thémata, $2^{\mathrm{a}}$ ed. 2014.

[17] Choza, J.: Neolithic genesis of Aristotelian Category of Quantity and the notion of Spirit, ISEEI, Oporto, 2014.

THÉMATA. Revista de Filosofía, $\mathrm{N}^{\circ} 50$ julio-diciembre (2014) pp.: 17-36 doi: 10.12795/themata.2014.i50.01 


\section{Intelección, idea y objetividad}

La experiencia cognoscitiva de lo real se va diferenciando progresivamente de la experiencia de lo sagrado, que es la vivencia de lo tremendo y fascinante, lo que provoca temor, un miedo especialmente sobrecogedor, y que a la vez provoca una atracción y una seducción por encima de cualquier experiencia ordinaria, y eso tanto en el sapiens del paleolítico como en el hombre actual.

Semejante experiencia de lo sagrado, que nunca queda desgajada del todo de la experiencia cognoscitiva profana, ha quedado descrita y expresada en unas obras ya clásicas. La de Rudolf Otto Das Heilige de $1917^{18}$, donde se describe como vivencia del Mysterium tremendum et fascinas, del misterio tremendo y fascinante, que provoca estupor, temor, fascinación y atracción al mismo tiempo. La de Eliade, Experiencias de la luz mística, la de Bataille El erotismo ${ }^{19}$ y unas cuantas más. En cada lengua y cultura esa experiencia y lo vivido en ella se ha designado con términos propios, pero con metáforas que se refieren a la luz, al bien o al amor. Por otra parte, casi siempre se ha descrito también como produciendo el mismo efecto sobre el ser humano y moviéndole a las mismas posturas corporales de genuflexión y abajamiento, adoración, plegaria, entrega y súplica.

Ahora es importante señalar la diferencia entre el Phanum y el Mysterium en orden a precisar la diferencia entre el correlato del intelecto humano y el del logos humano, porque no son el mismo, y aunque el lugar más apropiado para señalar la diferencia es la filosofía de la religión, también es preciso señalarla al describir la intelección.

El correlato del logos humano es uno, a saber, la totalidad de lo inteligible representable y expresable, y el correlato del intelecto humano es doble. Por una parte, el Phanum, la luz o el bien, que hace que la totalidad de lo real sea inteligible, representable y expresable y que tenga sentido, y por otra parte el Mysterium tremendum et fascinans, que excede con mucho la capacidad de articulación del logos humano en términos de contenido inteligible, representable y expresable, o en términos de contenido racional o científico, y que es el origen o el fundamento de la luz y el bien.

En primer lugar, el correlato del intelecto es, pues, por una parte, el Phanum, la luz, el bien o el ser, mediante los cuales el propio intelecto genera y articula los contenidos inteligibles, representables y expresables de la realidad, y, por otra parte, la totalidad de lo real representado, articulable en tales términos, que es el modo en que el intelecto genera el

[18] Otto, Rudolf: Lo santo. Madrid: Alianza, 1985.

[19] Eliade, M.: "Experiencias de la luz mística”, en Mefistófeles y el andrógino. Barcelona: Labor, 1984; Bataille, Georges: El erotismo. Barcelona: Tusquets, 2005.

THÉMATA. Revista de Filosofía, №50 julio-diciembre (2014) pp.: 17-36 doi: 10.12795/themata.2014.i50.01 
logos, es decir, la unificación de todos esos contenidos en un conocimiento teórico o representativo. Cuando la atención del intelecto se centra en el logos se debilita la experiencia de la vida, cuando se desarrolla la experiencia cognoscitiva, la experiencia de lo intencional y objetivo, se debilita la experiencia de la vida, del contacto inmediato con lo vivo.

En segundo lugar, el correlato del intelecto es el Mysterium tremendum et fascinans, es decir, 'lo sagrado', que no es representable ni articulable según el logos, según la razón o la ciencia, sino según la reflexión táctil, según el 'corazón', que puede articular en una unificación transformadora el mundo y lo sagrado.

El corazón tiene tanta potencia y alcance que puede llegar a romper el intelecto y a producir la locura: se puede enloquecer de amor, como muestran los poetas (especialmente Garcilaso de la Vega). El intelecto también puede llegar a romper el corazón, cuando percibe acontecimientos dolorosos por encima de la capacidad humana, y entonces se alma se apaga en otras formas de locura como la melancolía o la catatonia.

El 'corazón' es lo que los filósofos desde Gorgias y Platón hasta Wittgenstein, Heidegger y Levinas, y los antropólogos e historiadores desde Otto a Eliade y Geertz, han considerado que es lo que tiene como correlato a Dios (al cual se le puede amar más adecuadamente que conocer), y a la totalidad de lo real en cuanto que sacralizable por el hombre ${ }^{20}$.

Dicho más en concreto, el Mysterium tremendum et fascinans, lo sagrado, se corresponde con lo que es propio de o relativo a Dios, y con Dios mismo, según los significados que le dan los filósofos, antropólogos, historiadores de la religión, etc.

Para todos ellos lo sagrado y Dios mismo se sitúan más allá del alcance de las formalizaciones del intelecto, como un referente que es de alguna manera 'comprensible' cuando el intelecto y el 'corazón' adoptan una determinada actitud o abordan lo real según un determinado enfoque.

Gadamer en concreto, sostiene que el mito, la plegaria o las profesiones de fe, pertenecen a un orden de discurso en el que se habla de lo sagrado como fundamento del orden del intelecto, como origen del ser, de la luz y del logos, por eso carece de sentido valorarlos desde el punto de vista de un uso particular de la razón ${ }^{21}$. Por su parte, Geertz señala que la religión es el orden de apelaciones del ser humano que se abre cuando las situaciones existenciales desbordan toda capacidad de comprensión y llevan a una desesperación completa, el orden en el que se espera que puede haber una solución ante lo definitivamente

[20] Estos autores sostienen esta tesis en la medida en que consideran que el intelecto, impulsado por el amor o la caridad, tiene una capacidad cognoscitiva de mayor alcance que cuando opera en el monólogo objetivante (lo que Heidegger llama pensamiento representativo).

[21] Gadamer, H.G.: Mito y razón. Barceona: Paidos, 1997.

THÉMATA. Revista de Filosofía, №50 julio-diciembre (2014) pp.: 17-36

doi: 10.12795/themata.2014.i50.01 
insoluble (como por ejemplo la muerte). Por eso señala que lo que todas las religiones comparten es el dogma, "relativamente modesto, de que Dios no está completamente loco" 22 .

También podría decirse que la religión pertenece al orden de la experiencia táctil de la vida, al orden del corazón, y no al orden del conocimiento representativo de la realidad.

Puede suponerse que hay correspondencia y ajuste entre las capacidades intelectivas y comunicativas de los humanos y la realidad toda o el conjunto de las realidades inteligibles, que la realidad (el ser) supera al intelecto, o que el intelecto supera a la realidad (al ser). Todo ello se ha supuesto y se ha analizado en la historia de la filosofía occidental de modos muy explícitos y detallados en los siglos XIX y XX.

La luz hace visible lo iluminado, pero ella no necesita ser iluminada porque ya es luz. El intelecto tiene en parte la naturaleza de la luz, de lo actual, y en parte la de lo apagado, de lo que necesita ser encendido. El ente tiene solamente la naturaleza de lo iluminado, y el ser del ente también la de la luz (que sería la del ser como diferenciado del ente), y quizá la de una luz que enciende al intelecto apagado.

El ser desborda la capacidad conceptual y expresiva del intelecto, y su capacidad perceptiva, y en ese sentido se puede ensayar, como hace Heidegger, un análisis del correlato real del intelecto que no suponga una caída en los conceptos y en las reglas de articulación de conceptos, sino que le sostenga la mirada a la luz, al ser.

En ese caso, el intelecto humano puede referirse a su correlato real, más allá de lo conceptual, en el hombre actual y en los primeros sapiens, y entonces se encontraría con aquello que está más allá de los conceptos, es decir, más allá de lo articulado según el logos, más allá de lo organizado e inteligible racionalmente. En esa dirección lo que se capta son las nociones que abren los campos de lo informalizable, a saber, el caos, el mal, la nada, el poder, el ser, y la libertad. Más allá de esas nociones que abren los campos de lo informalizable se encontraría el Mysterium tremendum et fascinans.

El hombre se encontraría con que podría establecer con ese Mysterium una relación comunicativa afectiva, una relación comunicativa expresiva, y una relación meditativa reflexiva, y entonces se encontraría con que surgen y resurgen la religión, el arte y la filosofía como formas de relación del espíritu humano con lo que le supera, es decir, como formas del espíritu absoluto. Esto es lo que sucede de hecho, tanto en la vida ordinaria como en las experiencias extraordinarias, tanto en el paleolítico como en el neolítico y el postneolítico.

[22] Geertz, C.: "La religión como sistema cultural", en La interpretación de las culturas. Barcelona: Gedisa, 1992

THÉMATA. Revista de Filosofía, №50 julio-diciembre (2014) pp.: 17-36 doi: 10.12795/themata.2014.i50.01 
Estas capacidades subjetivas indican una cierta medida del intelecto del sapiens en todos los tiempos, actualizada en mayor o menor grado en unos que en otros. Por otra parte, dan pistas sobre el modo en que el Mysterium tremendum et fascinas es "experiencia táctil", experiencia vital, y no experiencia cognoscitiva o representativa, de lo que excede el intelecto humano, de lo que permite en determinados momentos volver al principio de la religión, del arte y de la filosofía, y del motivo por el cual dentro de la clase de "estados alterados de conciencia" entran a la vez fenómenos reflexivos, artísticos y religiosos, junto con otros de tipo patológicos.

Los creadores e innovadores de religiones, de corrientes artísticas, y de reflexiones filosóficas, cuando se han situado en un nivel suficientemente radical han descrito su experiencia como un encuentro con el origen, con el principio, y este origen ha sido caracterizado más en términos de Phanum, de luz, que en términos de idea. Por otra parte su actitud subjetiva ha sido descrita como adoración, veneración, fascinación, amor, locura divina (theia manía), subyugación y persuasión (Peitho), éxtasis, entusiasmo, admiración, y de otros modos análogos. Son expresiones no solamente utilizadas en las descripciones de sus experiencias por los profetas hebreos desde Moisés hasta Amós, o por Zaratustra y Confucio, que en el siglo VI a. C., predican las religiones de la interioridad, como señala Panikkar ${ }^{23}$. Son expresiones utilizadas por Homero y Píndaro, para dar cuenta de sus experiencias poéticas y creadoras, o por Parménides, Platón y Aristóteles, para referir sus experiencias teóricas contemplativas.

Esas expresiones vuelven a ser utilizadas por Francisco de Asis y por Teresa de Jesús en su descubrimiento del amor, por Leonardo y Velázquez al sentirse imitadores del creador, por Descartes junto a su estufa al descubrir el pensar como phanum en los inicios de la modernidad, y también en el siglo XX por Etty Hillesum, Ghandi y Martin Luther King para transmitir sus experiencias religiosas, por Rilke, Pessoa y Vallejo para cantar su piedad por Dios y por el hombre, y por Heidegger para señalar que el ser es el principio del pensar filosófico.

Posiblemente el hombre no puede evitar la tendencia a la representación del Phanun, o sea, a la idolatría, o, como diría Heidegger, a la metafísica ${ }^{24}$, aunque para otros autores, la creencia en que nunca puede haber una representación suficiente de Dios y de que el pensamiento es inane ante esa tarea, como es el caso de Hegel, significa una infravaloración del espíritu humano y del divino.

Cuando el intelecto humano se refiere a su correlato real, entonces se encuentra con aquello que está más allá de los conceptos, más allá de lo

[23] Panikkar, R.: El silencio del Buddha: introduccion al ateismo religioso. Madrid: Siruela, 2000. [24] Heidegger, M.: Carta sobre el humanismo. Madrid: Alianza, 2002.

THÉMATA. Revista de Filosofía, N50 julio-diciembre (2014) pp.: 17-36 doi: 10.12795/themata.2014.i50.01 
articulado según el logos, más allá de lo organizado y comprensible racionalmente, es decir, se encuentra con el horizonte de lo informalizable, como se ha dicho, a saber, el caos, el mal, la nada, el poder, el ser, y la libertad, que se pueden sistematizar en un cuadro como el que se presenta más adelante.

Lo informalizable es lo que en el plano trascendental remite a los problemas filosóficos fundamentales, y en el plano subjetivo provoca las reacciones biopsicológicas de miedo, angustia, ira y $\operatorname{otros}^{25}$. Más allá de esas nociones que abren los horizontes de formalización, los campos de lo informalizable y los ámbitos de sentido, se encuentra el Mysterium tremendum et fascinans, es decir aquello que está más allá de los horizontes de sentido, y que más que comprensible o amable es adorable y que por eso se adora. Adorar es la referencia originaria y adecuada a lo sagrado.

A lo largo de la historia de la filosofía y de las religiones, la conciencia intelectiva humana se ha experimentado a sí misma como A) experiencia estético-cognoscitiva y como B) experiencia estético-vital, y en ambos casos experimenta que tiene como correlato C) el logos de la realidad y la representación ideal de ese logos, D) El Phanum, la luz, el bien o el sentido que constituye el horizonte de comprensión de lo real, y E) el referente transcendente informalizable, origen y fundamento de la luz y del sentido.

La correspondencia entre experiencias subjetivas cognoscitivas y experiencias vitales y sus correlatos formales y formalizables, sus horizontes informalizables y el fundamento de esos horizontes más allá del abismo se puede representar en la siguiente tabla.

[25] Cfr., Burkert, W., La creación de lo sagrado. La huella de la biología en las religiones antiguas. Barcelona: Acantilado, 2009, pp. 27 y ss.

THÉMATA. Revista de Filosofía, $\mathrm{N}^{\circ} 50$ julio-diciembre (2014) pp.: 17-36 doi: 10.12795/themata.2014.i50.01 


\begin{tabular}{|l|l|l|l|l|}
\hline $\begin{array}{l}\text { A. Experiencia } \\
\text { estética } \\
\text { (del intelecto) }\end{array}$ & $\begin{array}{l}\text { B. Experiencia } \\
\text { vital } \\
\text { (del “corazón") }\end{array}$ & $\begin{array}{l}\text { C. Correlato } \\
\text { formalizable. } \\
\text { Logos real/ideal }\end{array}$ & $\begin{array}{l}\text { D. Horizonte } \\
\text { de sentido } \\
\text { informalizable }\end{array}$ & $\begin{array}{l}\text { E. Referente } \\
\text { trascendente } \\
\text { informalizable }\end{array}$ \\
\hline $\begin{array}{l}\text { 1. Estética, } \\
\text { Cognoscitiva } \\
\text { Religiosa }\end{array}$ & $\begin{array}{l}\text { Adoración, } \\
\text { Sobrecogimiento } \\
\text { (Chamanes). }\end{array}$ & $\begin{array}{l}\text { Fuerzas y } \\
\text { vivientes } \\
\text { naturales. } \\
\text { Ritos }\end{array}$ & Vida & $\begin{array}{l}\text { Fundamento de } \\
\text { la vida allende el } \\
\text { abismo }\end{array}$ \\
\hline $\begin{array}{l}\text { 2. Cognoscitiva, } \\
\text { Epistémica } \\
\text { Sapiencial }\end{array}$ & $\begin{array}{l}\text { Admiración } \\
\text { (Aristóteles) }\end{array}$ & $\begin{array}{l}\text { Logos } \\
\text { Epistémico y } \\
\text { Sapiencial }\end{array}$ & $\begin{array}{l}\text { Intelecto } \\
\text { Primero } \\
\text { Saber }\end{array}$ & Dios \\
\hline $\begin{array}{l}\text { 3. Cognoscitiva } \\
\text { Técnica, } \\
\text { Científica }\end{array}$ & $\begin{array}{l}\text { Duda } \\
\text { Certeza } \\
\text { (Descartes) }\end{array}$ & $\begin{array}{l}\text { Logos } \\
\text { dominador } \\
\text { Ciencia-Técnica }\end{array}$ & $\begin{array}{l}\text { Caos } \\
\text { Cosmos } \\
\text { controlable }\end{array}$ & $\begin{array}{l}\text { Gios creador } \\
\text { evidente }\end{array}$ \\
\hline $\begin{array}{l}\text { 4. Cognoscitiva } \\
\text { Moral }\end{array}$ & $\begin{array}{l}\text { Temor } \\
\text { Respeto } \\
\text { (Kant) }\end{array}$ & $\begin{array}{l}\text { Logos moral } \\
\text { Ley moral }\end{array}$ & $\begin{array}{l}\text { Bien } \\
\text { Mal }\end{array}$ & Juicio final \\
\hline $\begin{array}{l}\text { 5. Cognoscitiva } \\
\text { Existencial }\end{array}$ & $\begin{array}{l}\text { Angustia } \\
\text { (Kierkega ard, } \\
\text { Heidegger) }\end{array}$ & Logos existencial & Ser & $\begin{array}{l}\text { Misterio, } \\
\text { Abismo }\end{array}$ \\
\hline $\begin{array}{l}\text { 6. Cognoscitiva } \\
\text { interpersonal }\end{array}$ & $\begin{array}{l}\text { Llamada } \\
\text { (Levinas) }\end{array}$ & $\begin{array}{l}\text { Prójimo en todas } \\
\text { sus formas }\end{array}$ & Alteridad & $\begin{array}{l}\text { Misterio de } \\
\text { alteridad }\end{array}$ \\
\hline
\end{tabular}

En la historia de la cultura occidental la filosofía nace como reflexión de la experiencia cognoscitiva sobre sí misma cuando el pensamiento se ha distanciado mucho de la experiencia vital, cuando la vida ha dejado de sentirse a sí misma en la experiencia táctil originaria. Entonces el contacto con la vida, el tacto de ella, y la experiencia de ese contacto van quedando cada vez más alejadas de la conciencia intelectiva, más alejadas de la conciencia en general y más relegadas al "inconsciente".

Esa sería la respuesta a la pregunta de Zubiri en su estudio En torno al problema de Dios, en Naturaleza, Historia, Dios ${ }^{26}$, sobre el problema del ateísmo. El problema del ateísmo no es el problema de cómo es posible descubrir a Dios, sino del de cómo ha sido posible encubrirlo. Ha sido posible porque la conciencia intelectiva (occidental) ha desarrollado un plano de representación abstracta, un plano de formalización, donde representaba el logos de lo real, y donde se sentía obligada a representar los horizontes de formalización y sus fundamentos informalizables e irrepresentables para alcanzar la "totalidad". Pero una y otra vez se encontraba son la soberanía de su libertad, con el poder casi absoluto y casi divino de ella misma, en una especie de rivalidad con lo sagrado como la de Prometeo o de lucha contra el ángel como la de Jacob. En

[26] Zubiri, X.: Naturaleza, historia, Dios. Madrid: Sociedad de Estudios y publicaciones,1974.

THÉMATA. Revista de Filosofía, Nº50 julio-diciembre (2014) pp.: 17-36

doi: 10.12795/themata.2014.i50.01 
esos mundos eidéticos el hombre ha expresado su propia infinitud y su propia grandeza, y en esas creaciones del espíritu ha aprendido mucho de sí mismo. "He aquí que el hombre ha llegado a ser como uno de nosotros, en cuanto a conocer el bien y el ma” (Génesis 3, 22).

La conciencia intelectiva se interpreta a sí misma como espíritu y despliega los mundos eidéticos a los que interpreta a su vez como ámbitos del ser y de la realidad, más familiarizados y emparentados con los ámbitos de la objetividad universal que con los de la vida singular. El acontecimiento por el cual se generaba el logos ideal en los mundos eidéticos, gracias al peculiar vigor, luz o calor de los horizontes de sentido, se ha denominado intelección y se ha interpretado de diversos modos a lo largo de la historia de la filosofía occidental.

Pero el intelecto hace ruido al masticar, se escucha a sí mismo, y durante dos mil quinientos años los filósofos dotados de especial autoconciencia intelectiva, han percibido que al otro lado del mundo eidético, fuera de las placas tectónicas del universo intencional, por debajo del campo de la objetividad, el mundo de la vida y la vida misma emitían señales y provocaban interferencias que requerían ajustes en orden a una mayor y mejor comunicación entre experiencia cognoscitiva y experiencia vital, entre espíritu y vida, entre intelección y comprensión.

Es posible que a partir del siglo XXI se desplieguen nuevos universos eidéticos, aún insospechados, y que esos universos se integren más y más con la experiencia vital y con la realidad viva. Al menos parece haber señales de esa convergencia en la técnica y la ciencia, la filosofía y la religión del siglo XXI.

\section{Los momentos de la intelección. Una síntesis poética}

Es posible encontrar en la historia de la cultura occidental, y en la de otras culturas, formulaciones de esa unidad entre intelección y comprensión, entre espíritu y vida, a la que la conciencia intelectiva occidental parece abocada a finales del siglo XX. Una de esas formulaciones en que se describen los momentos de la intelección y la comprensión de un modo asequible para casi todos los humanos, es la Rima XVII, de Gustavo Adolfo Becquer:

Hoy la tierra y los cielos me sonríen, hoy llega al fondo de mi alma el sol, hoy la he visto... La he visto y me ha mirado...

¡Hoy creo en Dios! 


\section{1. "Hoy la tierra y los cielos me sonrien"}

Para el enamorado, el niño y el primitivo hay una fuente del sentido, una luz que ilumina la totalidad del campo vivencial y lo torna perceptible. Para el niño los padres, para el enamorado la amada y para el primitivo el cobijo y el alimento posibles son la sonrisa de la tierra y del cielo. Por eso la vida tiene sentido para ellos y la tierra es acogedora. Sin padres, sin enamorada, sin caza y cobijo la vida sería desesperación en el desierto, marcha hacia la extinción.

Es posible que el primitivo experimente el mundo formalizado por un poder favorable, mana, o que perciba las cosas formalizadas desde un poder o un alma frecuentemente benéfica (y que el shintoísmo japonés denomina kami).

\section{2. "hoy llega al fondo de mi alma el sol"}

Es posible que el enamorado, el niño y el primitivo, en diferentes episodios fructíferos y felices de sus vidas, experimenten ese poder benéfico como luz o como sol que ilumina lo profundo de su alma, y lo comprendan, comprendan que "a ti solo se llega por tu luz", como dice Pedro Salinas.

\section{3. "hoy la he visto... La he visto y me ha mirado..."}

Hay momentos en que el cielo se oscurece, y la tierra también. El sol se oculta, y no hay sentido. Entonces el enamorado, el niño y el primitivo languidecen. Hasta que la luz vuelve a salir otra vez.

La mitología japonesa refiere que al comienzo de los tiempos el sol se ocultó en unas grutas durante un largo diluvio, y que no salía. Pero que la diosa Amateratsu comenzó a interpretar una danza bellísima hasta que el sol, atraído por la curiosidad volvió a salir, volvió a iluminar. Entonces la amada, la madre y la vida se muestran al enamorado, al niño y al primitivo y los miran una y otra vez.

En otras culturas no es la belleza de la diosa, la sacerdotisa o la chamana la que hace salir el sol de nuevo, sino el poder del chaman, el bien de sanación que él puede producir.

\section{4. "HHoy creo en Dios!”}

Cada realidad del mundo y el conjunto de toda ella es lo que la amada y la madre han mencionado, han enseñado, han contado, han preparado. Cada cosa se percibe y se objetiva porque la amada o la madre la han tocado. El esquema de objetivación, de intelección, es una realidad personal y esa realidad personal es la fuente del sentido. 
$\mathrm{Al}$ comprender cada realidad y el conjunto de toda ella se siente que el mundo está en orden otra vez. Se siente la propia vida como una bendición y se siente el contacto con el fundamento de la vida más allá del abismo. Eso es la intelección y la comprensión.

Cuando la intelección y la comprensión fallan, el mundo retorna al caos de donde salió. Queda bien descrito en la letrilla de Antonio Machado:

"Tu calle ya no es tu calle, Es una calle cualquiera,

Camino de cualquier parte". 